\title{
O signo linguístico e o aspecto social no ISD
}

\author{
Fabiana Veloso de Melo Dametto ${ }^{1}$ \\ Marcia Cristina Corrêa ${ }^{2}$
}

\section{Resumo}

Este trabalho tem por objetivo analisar a abordagem do signo linguístico e do aspecto social, conforme postulado por Ferdinand de Saussure, dentro do modelo de análise de textos proposto pelo Interacionismo Sociodiscursivo (ISD), que tem Jean-Paul Bronckart como seu principal teórico. Com esse intuito, será analisada a forma como as principais bases teóricas que sustentam o ISD compreendem a linguagem, o signo linguístico e, consequentemente, o aspecto social dentro de uma perspectiva sócio-histórica. A partir dessa análise, concluímos que o aspecto social dentro da teoria saussureana não é o mesmo dentro das teorias de base do ISD que, apesar de partirem do mesmo conceito de signo linguístico, conforme postulado por Saussure, o entendem de forma mais ampla, pois assumem uma concepção mais heterogênea com relação à dimensão social.

Palavras-chave: Saussure. Signo linguístico. Interacionismo Sociodiscursivo (ISD) - aspecto social.

\begin{abstract}
The following paper aims to analyze the linguistic sign approach and the social aspect, as postulated by Ferdinand de Saussure, within the analysis model proposed by the Socio-Discursive Interactionism (SDI), which has Jean-Paul Bronckart as its main spreader. Considering this objective, it is analyzed the way the main theoretical bases that support SDI understand language and the linguistic sign and; consequently, the social aspect taking into consideration a socio-historic perspective. The analysis led to the conclusion that the social aspect within Saussure's theory is not the same within the theoretical bases of SDI that, despite the fact that both come from the same concept of linguistic sign according to Saussure, it is understood in a wider way, since they assume a more heterogeneous conception regarding the social dimension.
\end{abstract}

Keywords: Saussure. Linguistic sign. Socio-Discursive Interactionism (SDI) - social aspect.

\section{Introdução}

Este trabalho parte do conceito de linguagem para discutir como o signo linguístico e o aspecto social são entendidos dentro do quadro teórico do Interacionismo Sociodiscursivo, o qual tem Bronckart como seu principal teórico. Para tanto, inicialmente, serão apresentados os

\footnotetext{
${ }^{1}$ Mestrado em Programa de Pós-Graduação em Letras pela Universidade Federal de Santa Maria, Brasil(2010). E-mail: vm_fabi@yahoo.com.br

${ }^{2}$ Doutorado em Letras pela Universidade Federal do Rio Grande do Sul, Brasil(2002). E-mail: macrisco@gmail.com
} 
conceitos de linguagem, língua e signo linguístico, como postulados pela Teoria do Signo Linguístico, de Saussure (1916/2006). Na sequência, serão apresentados os pressupostos básicos do ISD e a forma como estes compreendem a linguagem. Por fim, será feita uma tentativa de aproximação entre os conceitos básicos da Teoria do Signo Linguístico e do ISD, de forma que se possa por em evidencia como cada um destes quadros teóricos compreende o aspecto social na constituição da linguagem humana.

\section{A Teoria do Signo Linguístico}

Saussure, no início do século XX, ao tomar a língua como norma de todas as outras manifestações da linguagem, define o objeto de estudo da linguística e, com isso, eleva-a ao status de ciência autônoma e independente. Considerado como o pai da linguística moderna, sua teoria tem servido de ponto de partida, ainda hoje, para as discussões a respeito da linguagem humana. O linguista suíço, no Curso de Linguística Geral (doravante, CLG; 1916/2006), organizado por seus alunos Charles Bally e Albert Sechehaye, estabelece quatro pares de conceitos dicotômicos: Língua versus Fala; Significado versus Significante; Paradigma versus Sintagma; e Sincronia versus Diacronia. É a partir desses pares de conceitos que este autor formula a Teoria do Signo Linguístico e estabelece bases sólidas para estudo da linguagem.

No CLG, Saussure define a linguagem como heterogênea, visto que seu estudo apresenta duas partes: “uma, essencial, tem por objeto a língua, que é social em sua essência e independente do indivíduo; [...] outra, secundária, tem por objeto a parte individual da linguagem, vale dizer, a fala [...]” (2006, p. 27). Assim, a linguagem é compreendida como língua mais fala. De acordo com o autor, “o exercício da linguagem repousa numa faculdade que nos é dada pela natureza” (2006, p.17), e essa faculdade é a de “constituir uma língua, vale dizer: um sistema de signos distintos correspondentes a ideias distintas” (2006, p.18).

Desse modo, Saussure (1916/2006) define a língua como: um dado social, portanto, coletivo; um produto social da faculdade de linguagem e, ao mesmo tempo, um conjunto de convenções necessárias, adotadas pelo corpo social para permitir o exercício dessa faculdade nos indivíduos; algo adquirido e convencional; parte essencial e social da linguagem; uma estrutura, um sistema de signos, ou seja, um conjunto organizado em que um elemento se define pelo outro (pela relação que estabelece com os demais signos). Para o autor, a língua é “algo que está em cada um deles [indivíduos], embora seja comum a todos e independente da 
vontade dos depositários. Esse modo de existência da língua pode ser representado pela fórmula: $1+1+1+1 \ldots=$ I (padrão coletivo)” (2006, p. 27).

A partir desse conceito de língua, Saussure define o signo linguístico como a união entre significante e significado. O laço que une essa associação é, segundo o autor, arbitrário, visto que "um indivíduo não somente seria incapaz, se quisesse, de modificar em qualquer ponto a escolha feita, como também a própria massa não pode exercer sua soberania sobre uma única palavra” (2006, p. 85). Além disso, Saussure acrescenta que “o signo linguístico escapa à nossa vontade” (2006, p. 85), pois ele é “um produto herdado de gerações anteriores” (2006, p. 86), ou seja, “é um produto de forças sociais” (2006, p. 88). No entanto, o autor esclarece que, em relação à língua, "situada, simultaneamente, na massa social e no tempo, ninguém lhe pode alterar nada e, de outro lado, a arbitrariedade de seus signos implica, teoricamente, a liberdade de estabelecer não importa que relação entre matéria fônica e as ideias” (2006, p. 90). Assim, conclui Saussure que “a língua se altera ou, melhor, evolui, sob a influência de todos os agentes que possam atingir quer os sons, quer os significados” (2006, p. 91).

Sem entrar na discussão do status dado à língua em detrimento da fala na teoria saussureana, apenas considerando a língua como um sistema de signos, e os signos como a união arbitrária entre significante e significado, nessa perspectiva, como afirma Bronckart (2007), a relação entre o sistema da língua e os atos constitutivos da fala (discurso) é da ordem de uma dialética permanente, visto que a fala é, de um lado, considerada a realização da potência da língua, mas, de outro, essa realização é que alimenta constantemente essa potência, de modo que uma língua não existiria ou desapareceria sem a fala.

Dentro da Teoria do Signo Linguístico, portanto, o aspecto social da linguagem é entendido como comum a todos, ou seja, é o padrão coletivo que se cristaliza através da fala, é “a forma duma soma de sinais depositados em cada cérebro, mais ou menos como um dicionário cujos exemplares, todos idênticos, fossem repartidos entre os indivíduos” (2006, p. 27). Saussure (1916/2006, p. 21) é bem claro ao afirmar que "se pudéssemos abarcar a totalidade das imagens verbais armazenadas em todos os indivíduos, atingiríamos o liame do social que constitui a língua. Trata-se de um tesouro depositado pela prática da fala em todos os indivíduos pertencentes à mesma comunidade [...]”.

\section{O Interacionismo Sociodiscursivo (ISD)}


Assim como a teoria saussureana, o Interacionismo Sociodiscursivo ${ }^{1}$ (doravante ISD) aborda o estudo da linguagem. O ISD fornece uma visão clara sobre a importância da linguagem verbal no funcionamento e no desenvolvimento humano, no quadro das atividades sociais (BUTTLER, 2009). Esse modelo de análise tem por objetivo propor uma teoria sobre as normas e condições de funcionamento da linguagem, considerando as práticas que se efetuam por meio dela, no intuito de organizá-la em modelos. A esse respeito, Bronckart (2007) esclarece que esses trabalhos filiam-se a uma Psicologia da Linguagem que se inscreve no quadro epistemológico da corrente das Ciências Humanas/Sociais, chamada de interacionismo social. Scarpa (2003), partindo de uma perspectiva histórica, afirma que essa teoria surge como uma proposta de Vygotsky, psicólogo soviético, para melhor dar conta do alcance social da aquisição da linguagem. De acordo com a autora, Vygotsky passa a exercer uma forte influência sobre os estudos em aquisição da linguagem nos anos de 1970; período em que se discutia o pensamento chomskyano como alternativa ao cognitivismo construtivista de Piaget, ou seja, quando o debate se estabelecia entre a tese de que certos aspectos de nosso conhecimento são inatos e a tese de que o conhecimento se origina no ambiente e é internalizado através dos sentidos.

Para o enfoque interacionista, no entanto, a aquisição da linguagem é compreendida como um processo pelo qual a criança se firma como sujeito da linguagem e pelo qual constrói ao mesmo tempo seu conhecimento do mundo. Além disso, acredita-se que esse processo realiza-se passando necessariamente pelo outro, pela interação com os demais membros do grupo no qual a criança está inserida. Disso decorre a tese de que linguagem e pensamento, a partir dessa perspectiva, devem ser estudados sob o mesmo prisma.

Além disso, Bronckart (1999) compara essa abordagem a outras, ao afirmar que esse modelo postula que não se pode explicar a conduta humana pelos aspectos neurobiológicos apenas, nem somente pelas limitações impostas pelo meio. Isso porque, diferentemente das ciências cognitivas, das neurociências e do behaviorismo, o interacionismo leva em conta a historicidade do ser humano, pela consideração das condições que dão origem a formas particulares de organização social, que se constituem a partir de formas de interação que têm por base o uso de um sistema de significação - semiótica.

Bronckart (1999) explica mais detalhadamente que o interacionismo social caracteriza-se por um posicionamento epistemológico geral. Tal afirmação se deve a seu caráter transdisciplinar, visto que o interacionismo constitui-se a partir de diversas correntes da filosofia e das ciências humanas, as quais sustentam a tese de que "as propriedades específicas das condutas humanas são o resultado de um processo histórico de socialização, 
possibilitado especialmente pela emergência e pelo desenvolvimento dos instrumentos semióticos” (BRONCKART, 1999, p. 21, grifos do autor). De acordo com Buttler (2009, p. 22), esse caráter transdisciplinar do interacionismo se deve ao fato de que o funcionamento humano integra diferentes aspectos, tais como o cognitivo, o social, o afetivo, o semiótico, o cultural, o fisiológico, entre outros.

Embora o grande número de referências teóricas que alicerçam a abordagem interacionista, Bronckart (1999) destaca que é no princípio da arbitrariedade do signo linguístico, postulado por Saussure (1916/2006), que se busca compreender os modos de organização das relações de interdependência entre a linguagem, as línguas e o pensamento humano. Por fim, apesar de considerar a importância da obra de Piaget para a psicologia, o interacionismo faz uma releitura crítica de sua teoria da construção do psicológico, ao mostrar a relação entre aspectos sociais e a construção das capacidades cognitivas da criança. Com relação às teorias do desenvolvimento, Bronckart afirma que são essencialmente os trabalhos de Vygotsky que servem de base para o interacionismo.

Para desenvolver a sua própria abordagem, então, o ISD parte do interacionismo social e, dessa forma, inscreve-se como uma "variante e um prolongamento" desse quadro teórico. Bronckart adverte, no entanto, que o ISD não deve ser confundido com uma corrente propriamente linguística, nem com uma corrente psicológica ou sociológica. O ISD, como esclarece o autor, "quer ser visto como uma corrente da ciência do humano”, que parte do pressuposto de que "o problema da linguagem é absolutamente central ou decisivo para essa ciência do humano”. Assim, busca demonstrar que “as práticas linguageiras situadas (ou os textos-discursos) são os instrumentos principais do desenvolvimento humano, tanto em relação aos conhecimentos e aos saberes quanto em relação às capacidades do agir e da identidade das pessoas”. (BRONCKART, 2006, p. 10, grifos do autor)

Partindo desse pressuposto, interessou-nos analisar como se dá a abordagem do signo linguístico e do aspecto social dentro desse modelo de análise textual que se propõe a demonstrar o papel central da linguagem no desenvolvimento humano e, em especial, nas mediações educativas e/ou formativas (BRONCKART, 2006, apud BUTTLER, 2009).

\subsection{Pressupostos básicos do ISD}

Para que se possa entender como o aspecto social é entendido pelo ISD, é preciso retomar os pressupostos básicos desse quadro teórico. Com relação a isso, é necessário 
apresentar, em linhas gerais, a investigação em torno das propostas dos russos Lev Vygotsky (1934/1985), Mikhail Bakhtin (1978/1984) e V.N. Volochinov² (1929/1981), os quais sustentam a perspectiva sócio-histórica do ISD. Além deles, com relação à concepção de linguagem, o ISD inspira-se em Humboldt (1987) e Coseriu (2001). No intuito de compreender os aspectos característicos da atividade humana, o ISD toma como princípio a tese de Leontiev (1979), e, para interpretá-la, parte da teoria dos mundos representados, de Habermas (1987) que, por sua vez, parte dos estudos de Saussure sobre o signo linguístico para compreender os processos de constituição e transmissão das representações.

A teoria do desenvolvimento, defendida por Vygotsky, que embasa a abordagem psicológica da linguagem no quadro epistemológico do ISD, postula que, mais do que um ser simplesmente biológico, o homem fundamenta-se a partir da história, num trajeto que vai do social para o individual, e o seu pensamento consciente é formado a partir da apropriação e da interiorização dos signos de uma língua. Além disso, partindo de uma teoria de base marxista (dialética), esse autor trabalha com o conceito de mediação em duas vertentes (ontogênese e filogênese ${ }^{3}$ ), uma vez que compreende que o funcionamento psicológico, tal como as relações de trabalho, ocorre de maneira mediada, através da utilização de instrumentos. Assim, entende que, pela inserção do sujeito em uma dimensão coletiva e através da interação com os demais membros do grupo social de que faz parte, o pensamento, pela ação da linguagem, torna-se verbal.

Nessa teoria, portanto, segundo Cardoso (2000), acredita-se que a linguagem tem como função primeira, tanto no adulto como na criança, a comunicação, ou seja, o contato social e o poder de influência sobre a conduta dos demais indivíduos. A autora esclarece, ainda, que a formulação sobre a constituição social do desenvolvimento envolve a formação da consciência individual, passando pela relação com o outro e com o contexto social, relação sempre mediatizada por mecanismos semióticos.

Com relação à concepção de linguagem, o ISD inspira-se em Humboldt (1974) e Coseriu (2001), uma vez que ambos também enfocam o aspecto histórico e social da linguagem. Para o primeiro autor, “assim como a linguagem só existe nas línguas naturais, estas, por sua vez, só existem nas práticas verbais” que visam à comunicação entre os indivíduos. Sendo assim, ela é compreendida como atividade social, como um agir "dirigido a” (BRONCKART, 2008, p. 71). Humboldt (1974) define a linguagem como "uma atividade permanente dos humanos (Energeia), como um processo dinâmico histórico” (BULEA, 2010, p. 49, grifos da autora). O que implica entendê-la como inerente à atividade humana, como herança das gerações anteriores (caráter histórico), mas ao mesmo tempo, como produto da 
apropriação de um indivíduo particular, portanto, sujeita a movimentações/mudanças/evoluções (caráter dinâmico). Para o segundo autor, Coseriu, a linguagem apresenta a particularidade de ser atividade significante, "sempre marcada pela alteridade; ela é o fato de que 'sujeitos' se abrem a outros 'sujeitos'”, como ressalta Bronckart (2008, p. 74). O que significa dizer que a linguagem pressupõe a atividade que, por sua vez, pressupõe sujeitos envolvidos, isto é, a relação com o outro.

Para compreender os aspectos característicos da atividade humana, o ISD toma como princípio a tese de Leontiev (1979 apud BRONCKART, 1999/2007, p. 31-32). Esse autor sustenta que a noção geral de atividade refere-se às organizações características do comportamento dos indivíduos (funções de sobrevivência das espécies, por exemplo), por meio das quais eles têm acesso ao meio em que estão inseridos (contexto) e, desta forma, podem construir conhecimentos (representações internas) sobre esse espaço. Logo, nessa visão, entende-se a atividade como possibilidade de agir sobre o meio, como conjuntos de relações entre indivíduos e meio, caracterizando-se como "elemento principal ou fundamental do ambiente humano” (BRONCKART, 2008, p. 112).

Essas atividades, na espécie humana, são variadas e se diferenciam também pela complexidade, visto que, além de contarem com a cooperação entre os indivíduos (como ocorre com outros animais), elas são mediadas por interações verbais e vão além das exigências imediatas de sobrevivência (nutrição, reprodução, segurança, etc.). Assim, essa atividade social humana caracteriza-se e é mediada pelo que Habermas (1987) chama de agir comunicativo. À sua emergência, atribui-se o papel de constituição do aspecto social e das unidades representativas do pensamento humano (psiquismo), ou seja, dos signos (BRONCKART, 1999, p.31-33).

Bronckart acrescenta que Habermas defende a seguinte ideia: é por meio da linguagem que se constroem coletivamente as formas de conhecimento (representações) sobre o meio, uma vez que é através do agir comunicativo que o homem transforma o meio em mundos representados. Para Habermas, "qualquer atividade se desenvolve levando-se em consideração determinadas representações coletivas que se encontram organizadas em três sistemas chamados mundos formais ou representados” (BRONCKART, 2008, p. 21-22, grifo do autor). Com base nisso, nessa teoria, postula-se que qualquer atividade se desenvolve em um mundo físico (objetivo), no qual existem normas estabelecidas por grupos específicos (social) e, necessariamente, envolvem pessoas (subjetivo). Assim, o conhecimento sobre esses aspectos contextuais é levado em conta pelos indivíduos engajados em uma atividade. 
Ademais, como esclarece Bronckart (2008), Habermas acredita que a produção e transmissão dessas representações são garantidas pelo estatuto social do signo linguístico, como postulado por Saussure (1916). Dessa forma, como explica Bronckart (1999, 2006, 2008), de acordo com a tese de Habermas, os signos remetem, primeiramente, a aspectos do mundo físico (mundo objetivo); depois, a aspectos referentes às modalidades convencionais de cooperação entre membros do grupo (mundo social); e, por fim, a aspectos ligados às características próprias de cada um dos indivíduos engajados na tarefa (mundo subjetivo). Essas três ordens de conhecimentos formam o contexto específico em que se realizam as atividades de linguagem.

Quanto ao modo de organização e realização, Bronckart (1999) explica que a atividade de linguagem verbal apresenta-se em formas de discursos ou de textos ${ }^{4}$, sempre manifestados no quadro de uma língua natural particular. Disso decorre a adesão do ISD aos fundamentos metodológicos da análise dos discursos propostas por Bakhtin e Volochinov. Desses pesquisadores, explica Bronckart (2007, p. 21), “tomou-se uma abordagem descendente dos fatos linguageiros, que coloca em primeiro plano a práxis, isto é, a dimensão ativa, prática, das condutas humanas em geral e das condutas verbais em particular”. Logo, uma abordagem que também vai do social para o individual, assim como a de Vygotsky sobre o desenvolvimento humano.

De Bakhtin, “tomou-se o conceito das formas de enunciação e a proposta da noção de gêneros do discurso relacionados aos tipos de atividades humanas, a descrição e a análise de diversas propriedades dos gêneros primários e secundários” (BRONCKART, 2007, p. 22, grifos do autor). Com base nisso, dentro da Teoria da Enunciação, de Bakhtin, a linguagem é responsável pela emergência de formas linguísticas mais ou menos estáveis que garantem, juntamente com o uso de um código comum - uma língua natural -, o exercício dessa faculdade humana, o que é chamado pelo autor de gênero discursivo.

De Volochinov (1929/1977), o ISD considerou a tese de que os signos-ideias "não podem provir da atividade dos indivíduos isolados; ao contrário, são necessariamente, resultado dos discursos produzidos no quadro de interações sociais” (BRONCKART, 2008, p. 75). Por isso, explica Bronckart que, para Volochinov,

[...] os discursos apresentam sempre um caráter dialógico: eles se inscrevem em um horizonte social e se dirigem a um auditório social: "toda palavra tem duas faces. Ela é determinada tanto pelo fato de que procede de alguém quanto pelo fato de que é dirigida a alguém. Ela é o produto da interação do locutor e do ouvinte [...]. (VOLOCHINOV, 1977 apud BRONCKART, 2008, p. 75) 
Nessa perspectiva, a concepção de linguagem constrói-se a partir do conceito de dialogismo. Linguagem e aspectos sociais (meio e contexto) estão intimamente ligados, uma vez que se defende que a relação social se estabelece a partir do diálogo entre o eu e a alteridade, ou seja, a interação pressupõe o outro. Assim, nessa visão, postula-se que:

Toda palavra comporta duas faces. Ela é determinada tanto pelo fato que procede de alguém, como pelo fato de que se dirige para alguém. Ela constitui justamente $o$ produto da interação do locutor e do ouvinte. Toda palavra serve de expressão a um em relação ao outro. Através da palavra, defino-me em relação ao outro, isto é, em última análise, em relação à coletividade. A palavra é uma espécie de ponte lançada entre mim e os outros. Se ela se apóia em mim numa extremidade, na outra, apóia-se sobre o meu interlocutor. (VOLOCHINOV/BAKHTIN, 1995, p.113, grifos do autor)

A partir do que até aqui foi apresentado, fica claro que, no ISD, a linguagem ocupa um papel central:

a) com base em Vygotsky, pelo fato de ela apresentar um caráter organizador do pensamento, ou seja, por ela ser responsável pela emergência e desenvolvimento da consciência humana;

b) com base em Volochinov/Bakhtin, por seu aspecto dialógico (discursivo), isto é, ela é o produto de interações sociais e é responsável pela emergência de formas linguísticas mais ou menos estáveis - os gêneros discursivos;

c) com base em Humboldt, por ela ser compreendida como atividade social, como um agir dirigido a alguém, como um processo dinâmico e histórico;

d) com base em Coseriu, por ela apresentar a particularidade de ser atividade significante para alguém; ela pressupõe a atividade que, por sua vez, pressupõe sujeitos envolvidos;

e) com base em Habermas, por ela ser considerada como um agir comunicativo que constitui a atividade social humana e é responsável pela produção e transmissão das representações dos indivíduos - pelo caráter social do signo linguístico.

Com base nesse levantamento, fica evidente que o aspecto social, dentro do quadro teórico do ISD, é compreendido como interação, isto é, ele pressupõe a relação com o outro, pois é compreendido como um agir dirigido ao outro.

\section{A abordagem do aspecto social}


A abordagem do aspecto social do signo linguístico, dentro do ISD, é o ponto de partida para suas discussões acerca da linguagem humana. Neste sentido, cumpre destacar uma questão importante levantada por Bronckart (2007). Segundo este autor, a análise da Teoria do Signo Linguístico leva a formular a seguinte observação:

[...] a de que essa análise nos dá base essencial para a visão vygotskyana do desenvolvimento. De um lado, ela mostra que o trabalho psíquico constitutivo dos signos nada mais é que o trabalho constitutivo das unidades do pensamento [...]. Por outro lado, essa análise mostra que essa constituição das unidades de pensamento é necessariamente marcada pelo social, isto é, pelo sistema de acordos particulares que predomina em uma determinada sociedade. (BRONCKART, 2007, p. 30)

Vale lembrar que, para Saussure (1916/2006, p.130-131), o papel característico da língua é “servir de meio intermediário entre o pensamento e o som”, visto que o pensamento, “caótico por natureza, é forçado a precisar-se ao se decompor”, e a língua elabora suas unidades (os signos) ao se constituir "entre duas massas amorfas”.

Conforme explica Bronckart (2007, p. 22), para Vygotsky (1934/1997), “é a interiorização dos signos de uma língua natural que é constitutiva do pensamento consciente”. Percebe-se, assim, uma aproximação entre essas teorias, visto que estabelecem uma relação entre pensamento e linguagem.

No entanto, aproximação não significa dizer que essas teorias, apesar de considerarem o papel dos signos na emergência do pensamento e seus aspectos sociais, compartilhem do mesmo conceito de social. Entendemos que, para Saussure, apesar de esse termo não ter sido amplamente trabalhado dentro de sua teoria, ao falar de social, não há uma referência ao papel fundamental do outro nos processos relacionados à faculdade humana da linguagem, mas apenas ao fato de a língua, enquanto sistema de signos, ser comum a todos os membros de uma determinada comunidade linguística, ou seja, ela é o padrão depositado em casa cérebro. Diferentemente desse ponto de vista, as teorias que servem de base para o ISD, quando se referem à natureza social do signo, apesar de levarem em conta o fato de o código apresentar traços comuns a todos os indivíduos, estão considerando, acima de tudo, a língua e, consequentemente, o signo, como instrumento de interação entre o eu e o outro. A linguagem, vista dessa forma, como explica Cardoso (2000), implica um alguém falando a outro alguém e estabelecendo, assim, uma interação dialógica e comunicativa através dos mecanismos semióticos.

\section{Considerações finais}


Tomando por base as discussões até aqui apresentadas, chegamos à conclusão de que o social dentro da teoria saussureana não é o mesmo social dentro das teorias que servem de base para o ISD. Em Saussure, o social significa comum a todos os membros de uma mesma comunidade linguística, ou seja, o social é relativo a um grupo de pessoas que dominam um mesmo código e, desse modo, atribuem aos significantes os mesmos significados. No ISD, diferentemente, o social é relativo à interação que é mediada pela linguagem, logo, pressupõe o outro, seja como ponto de partida para internalização dos aspectos culturais, ou como o sujeito para quem o discurso é construído.

Por fim, vale destacar que acreditamos que as teorias que servem de base para o ISD avançam ao incorporarem à sua teoria uma concepção mais heterogênea com relação à dimensão social. Entendemos que, nessas perspectivas, o sistema (a língua) e a realização empírica (a fala) não mais são vistos como dimensões separadas, dicotômicas, assim como o outro não é simplesmente aquele com o qual o eu compartilha um repertório comum de signos; sistema e realização compõem, de modo interdependente, as atividades de linguagem.

\footnotetext{
${ }^{1} \mathrm{O}$ Interacionismo Sociodiscursivo surge como uma nova abordagem da didática dos textos, a qual tem servido de base para inúmeros trabalhos de pesquisadores brasileiros preocupados, especialmente, com atividades e ferramentas de ensino, seja de língua materna, L2 ou mesmo formação de professores. Seu modelo de análise de texto constitui-se a partir dos estudos empreendidos pelo grupo de pesquisadores, em especial Bronckart, Schneuwly e Dolz, da Unidade de Didática de Línguas da Faculdade de Psicologia e Ciências da Educação da Universidade de Genebra. Embora as pesquisas desses autores apresentem focos diferenciados, eles compartilham da mesma tese ao propor a análise dos textos. Dessa forma, de acordo com Machado (2005), sobre a liderança de Bronckart, ficaram as análises da morfogênese das ações em diferentes situações de trabalho.

${ }^{2}$ Bronckart (2007, p. 76), esclarece que, “devido às turbulências sociopolíticas e científicas que caracterizaram a União Soviética no período entre guerras", durante muito tempo, foi difícil determinar os verdadeiros autores dos trabalhos produzidos nas décadas de 1920 e 1930, pelo chamado Círculo de Bakhtin. No entanto, o autor afirma que, hoje, a paternidade de certos trabalhos foi atribuída a Volochinov e Medvedev. Acreditou-se, por longo tempo, que esses pesquisadores haviam apenas emprestado seus nomes, com o objetivo de proteger a Bakhtin. Assim, esclarece o autor que a autoria da obra Marxisme et philosophie du langage deve ser atribuída somente a Volochinov.

${ }^{3}$ Ontogênese, de acordo com o dicionário Houaiss (2009), refere-se à ontogenia, termo da biologia que significa entender o desenvolvimento de um indivíduo desde a concepção até a maturidade. Já a Filogênese refere-se à filogenia e significa história evolutiva de uma espécie ou qualquer outro grupo taxonômico.

${ }^{4}$ A conceitualização desses termos (texto e discurso) é discutida detalhadamente em Bronckart 1999. No capítulo 2, o autor adota a seguinte terminologia: texto é "toda unidade de produção de linguagem situada, acabada e auto-suficiente (do ponto de vista da ação ou da comunicação). Na medida em que todo texto se inscreve, necessariamente, em um conjunto de textos ou em um gênero, adotamos a expressão gênero de texto em vez de gênero de discurso" (p.75). Sendo assim, no capítulo 5, o autor define a noção de texto como "formas comunicativas globais e 'finitas' constituindo os produtos concretos das ações de linguagem, que se distribuem em gêneros adaptados às necessidades das formações sociodiscursivas [sócio-langagières], permanecendo esses gêneros, cujo número e cujas fronteiras são por essência indeterminados, à disposição, como modelos, nesse construto que é o intertexto" (p.149). Já o termo discurso é empregado pelo autor apenas quando se refere aos mundos discursivos, como no capítulo 5, no qual é afirmado que os tipos de discursos são entendidos "como formas linguísticas que são identificáveis nos textos e que traduzem a criação de mundos discursivos específicos [...]” (p.149). Logo, entendo que, para o ISD, de acordo com Bronckart (1999), texto e discurso constituem unidades diferentes de análise, pertencendo assim a níveis de abordagem igualmente distintos.
} 


\section{Referências}

BAKHTIN, Mikhail. Estética da criação verbal. São Paulo: M. Fontes, 1992.

(Volochinov). Marxismo e filosofia da linguagem: problemas fundamentais do método sociológico na ciência da linguagem. Tradução de Michel Lahud e Yara Frateschi Vieira. São Paulo: Hucitec, 1995.

BRONCKART. Jean-Paul. Atividade de linguagem, textos e discurso: por um interacionismo sócio-discursivo. São Paulo: Educ, 1999.

. Jean-Paul. "Atividade de linguagem em relação à língua - homenagem à Ferdinand de Saussure”. In: GUIMARÃES, A. M. M; MACHADO, Anna R.; COUTINHO, A.(org). O interacionismo sociodiscursivo. Campinas, SP: Mercado de Letras, 2007.

O agir nos Discursos: das concepções teóricas às concepções dos trabalhadores. Tradução Anna Rachel Machado e Maria de Lourdes Meirelles Matncio (orgs.) Campinas, SP: Mercado de Letras, 2008.

BULEA, Ecaterine. Linguagens e efeitos: desenvolvimentais da interpretação da atividade. Campinas, SP: Mercado de Letras, 2010.

BUTTLER, Daniella Barbosa. A imagem esfacelada do professor: um estudo em textos de revistas. Tese (Doutorado) - Pontifícia Universidade Católica de São Paulo, 2009.

CARDOSO, Cancionila Janzkovski. Da oralidade à escrita: a produção do texto narrativo no contexto escolar. Cuiabá, MT: UFMT/INEP/MEC, 2000.

COSERIU, E. L’homme et son langage. Louvain: Peeters, 2001.

FREITAS, Maria T. de Assunção. Vygotsky e Bakhtin: psicologia e educação: um intertexto. São Paulo: Ática, 2003.

HABERMAS, J. Théorie de l’agir communicationnel. Paris: Fayard, 1987.

HUMBOLDT, W. Von Introduction à l’uvre sur lê kavi. Paris: Seuil, 1835[1974].

LEONTIEV, A. N. Uma contribuição à teoria do desenvolvimento da psique infantil. In: VYGOTSKY, L.S., LURIA, A. R., LEONTIEV, A. N. Linguagem, desenvolvimento e aprendizagem. São Paulo: Ícone: Editora da USP, 1998. p. 59-84. 
MACHADO, Anna Raquel. “A perspectiva interacionista e sociodiscursiva de Bronckart”. In: MEURER, J. L.; BONINI, A.; MOTTA-ROTH, D. (Orgs). Gêneros: teorias, métodos e debates. São Paulo: Parábola, 2005. p. 237-259.

SAUSSURE, Ferdinand de. Curso de Lingüística Geral. Trad. de Antonio Chelini, José Paulo Paes e Izidoro Blikstein, São Paulo, Cultrix/USP, 2006.

SCARPA, Ester Mirian. “Aquisição da linguagem”. In: MUSSALIM, Fernanda, BENTES, Anna Christina. Introdução à lingüística: domínios e fronteiras. v. 2. 5. ed. São Paulo: Cortez, 2006. 